\title{
Self-Locking Stand-Alone Cage Used from Opposite Approach for the Treatment of Adjacent Segment Disease After an Anterior Cervical Corpectomy and Fusion
}

\author{
Hu WEI, Kan SHUNLI, Jiang ZEHUA, Zhang TENGFEl, Liu YIDONG, Zhu RUSEN \\ Tianjin Union Medical Center, Department of Spine Surgery, Tianjin 300121, China \\ Corresponding author: Zhu RUSEN zrsspine@163.com
}

\section{ABSTRACT}

AIM: To investigate the efficacy and safety of the self-locking stand-alone cage used from opposite approach for the treatment of adjacent segment disease (ASD) after an anterior cervical corpectomy and fusion (ACCF).

MATERIAL and METHODS: In this study, we retrospectively analyzed the clinical data of 8 cases of ACCF in the treatment of ASD cervical spondylopathy. All patients received self-locking stand-alone cage treatment. At different time points, the clinical status was evaluated using the Japan Orthopedic Association (JOA) score, JOA recovery rate (RR), and Neck Disability index (NDI) score. X-ray measurements included C2-C7 Cobb angle, fusion segment angle (FSA), cervical vertebral bow depth (VBP), and height of surgical segment (HOS). Statistical imaging parameters of sagittal cervical spine. Bone graft fusion in all self-locking stand-alone cage segments was evaluated.

RESULTS: All operations were successfully completed, and no infection, epidural hematoma, or rupture of the dura mater were observed in all patients. Compared with pre-operation, the JOA and NDI scores at 3 months and at the last follow-up were significantly improved $(p<0.05)$. The JOA recovery rate between the final follow-up and preoperatively was $64.8 \pm 5.2 \%$. One patient had dysphagia postoperatively, but was resolved after 3 months. Three months after surgery, the sagittal radiographic outcomes improved significantly and were well maintained during the final follow-up.

CONCLUSION: The self-locking stand-alone cage is a reliable and effective method used from the opposite approach for the treatment of ASD after ACCF in terms of JOA and NDI scores. The cervical alignment correction is considered satisfactory.

KEYWORDS: Cervical spondylosis, Anterior cervical corpectomy and fusion (ACCF), Adjacent segment disease (ASD), Imaging parameters, Reoperation, Outcomes, Dysphagia

ABBREVIATIONS: ASD: Adjacent segment disease, ACCF: Anterior cervical corpectomy and fusion, JOA: Japanese Orthopedic Association, RR: Recovery rate, NDI: Neck Disability Index, FSA: Fusion segmental angle, HOS: Height of operation segment, VBP: Vertebral bow depth, MRI: Magnetic resonance imaging

\section{INTRODUCTION}

$\mathrm{C}$ ervical spondylotic myelopathy (CSM) is a common cervical spine pathology $(6,16)$, which have been widely surgically treated with anterior cervical corpectomy and fusion (ACCF) and anterior cervical discectomy and fusion (ACDF) as anterior approaches in the past years $(29,37)$. ACCF provides improved visualization over ACDF in removing osteophytes and ossified posterior longitudinal ligament $(32,35)$.
Hu WEI : 0000-0002-5709-3987

Kan SHUNLI (1) : 0000-0002-7162-7420

Jiang ZEHUA (D): 0000-0002-5336-740X
Zhang TENGFEI (D) : 0000-0002-8924-1526

Liu YIDONG (D): 0000-0002-4449-8096

Zhu RUSEN (1) : 0000-0002-4076-3171 
ACCF achieved satisfactory clinical outcomes during the short-term follow-up. In the long-term follow-up, the degenerative changes at the adjacent level were recorded and the clinical effect was not satisfactory $(21,22)$. Some scholars define the correlation between the development of adjacent segment disease (ASD) as radiculopathy or myelopathy and the new imaging evidence of degenerative changes at a level adjacent to the previous cervical joint replacement (14). Compared with ACDF, the incidence of ASD after ACCF is higher, some of the risk factors include general condition and patient's lifestyle, surgical fusion segment, and type of bone graft fusion $(13,15)$.

In patients with ASD after ACCF, if patients have symptoms including sensory and motor disturbances that affected their daily life and conservative treatment is ineffective, surgery is required $(10,26)$. If surgeon chose to revise the original incision, due to scar, the operative anatomy is unclear, the incidence of soft tissue injury is higher, and the replacement of plates or screws can cause loosened internal fixation; therefore, surgeons should try their best to choose the most effective, less complicated, and low-bundled payment treatment. It is a good choice to perform surgery from the opposite approach. Based on this consideration, we conducted a retrospective study of patients with cervical spondylotic myelopathy treated with ACCF and were followed up for at least 1 year. This study aimed to assess the clinical and radiological results of the selflocking stand-alone cage used from the opposite approach for the treatment of ASD after ACCF.

\section{MATERIAL and METHODS}

\section{Patient Population}

This study was approved by the Ethics Committee of The Tianjin Union Medical Center, and all patients were informed about this study and signed informed consent. Eight patients underwent ACCF revision for ASD between January 2016 and December 2018. All patients did not show signs of adjacent segment degeneration during the first surgery (including imaging degeneration or clinical symptoms of adjacent segments).

All patients had new radiculopathy or myelopathy symptoms and new imaging evidence of degenerative changes. No symptom improvement was noted after 6 months of conservative treatment.
Exclusion criteria are listed below: (1) continuous retrovertebral compressive pathologies at two or more adjacent vertebral levels; (2) spinal cord compression due to posterior bony pathology (such as ossification of ligamentum flavum); (3) developmental stenosis; (4) spine trauma, congenital deformity, tumor spinal pathologies, and chronic systemic illnesses such as rheumatoid arthritis and neurodegenerative diseases; and (5) ASD that needed to be decompressed using a posterior approach.

\section{Surgical Procedure}

Operations were performed in supine position by the same experienced spine surgeon at a single institution. Under general anesthesia, all patients were managed with cervical anterior Smith-Robinson incision in opposite approach (total left-sided anterior approach) compared to the last surgery. The microscope was used in all patients during the procedure. The posterior longitudinal ligament and osteophytes were removed using a rongeurs or a drill, establishing adequate exposure and decompression of the dura mater and nerve root origins. After a sufficient decompression, the adjacent vertebral endplates were scraped to remove the cartilage. The bony endplate was preserved to prevent cage subsidence. A self-locking stand-alone cage (ROI-C, Zimmer Biomet, Austin, TX, USA, Figure 1A-D) packed with allogeneic bone (pharmaceutical group investment limited corporation, Hangzhou, China) were then implanted into the intervertebral space. In addition, cervical anchoring clips were placed into the vertebra through the anterior part of the stand-alone cage to ensure primary stabilization, and if the plate or screw in the last surgery was blocked, at least one anchoring clip was placed. Patients were encouraged to exercise as tolerated immediately after the operation with a soft collar. The collar was applied within the first 3 months postoperatively.

\section{Clinical Evaluation}

Data collected included age, sex, body mass index, comorbidity, smoking, bone density, operated levels, operative details, ACCF segment, and ROI-C segment. During the follow-up, the Japanese Orthopedic Association (JOA) scoring system was used to assess the neurological status (34). The JOA recovery rate $(R R)$ was assessed using the rationale by Hirabayashi et al. (11). The Neck Disability Index (NDI) scoring system was used to evaluate neck function (24). The incidence of dysphagia was calculated using the Bazaz grading system (2).

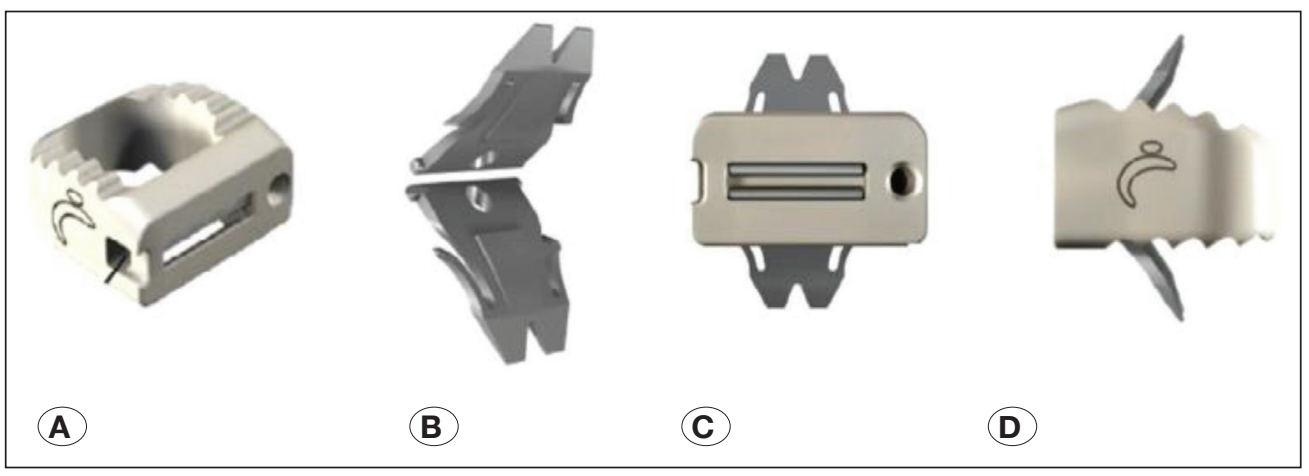

Figure 1: The self-locking stand-alone PEEK cage (ROI-C) consisted of an interbody spacer and two anchoring clips. A) The interbody spacer. B) Anchoring clips. C) Anterior view. D) Lateral view. 


\section{Radiological Evaluation}

All patients underwent standard cervical radiography preoperatively, 3 months postoperatively, and at the last follow-up. The $\mathrm{C} 2-\mathrm{C} 7 \mathrm{Cobb}$ angle segmental angle, fusion segment angle (FSA), and height of operation segment (HOS) were measured, and Borden's method was used to measure the cervical vertebral bow depth (VBP) (Figure 2A-D) (7). Bony fusion was defined as the absence of a radiolucent gap between the endplate and the graft, must be less than $2^{\circ}$ between the extension and flexion radiographs (23).

\section{Statistical Analysis}

All analyses were performed using the SPSS for Windows version 19.0 (SPSS Inc., Chicago, IL, USA). The mean and standard deviation were determined for quantitative data. Independent sample t-tests were performed for intergroup comparisons, and paired t-test was used to compare preand postoperative data. P-values of less than 0.05 were considered statistically significant.

\section{RESULTS}

Eight patients with ASD who underwent ACCF were identified. All surgeries were successfully performed, and no infection, epidural hematoma, and cerebrospinal fluid leakage were observed in all cases. The mean duration of post-operation follow-up was $16.5 \pm 4.5$ months. None of the patients were lost to follow-up. No patients underwent reoperation. The mean operative time was $75.6 \pm 18.7$, and the mean blood loos and postoperative hospital stay were $25.5 \pm 20.5$ and $2.5 \pm 1.5$, respectively (Table I). Corpectomy was performed during the last ACCF surgery at C4 levels in 3 patients and C5 levels in 5 patients. The ROI-C segment was at C4/C5 levels in 3 patients and $\mathrm{C} 6 / \mathrm{C} 7$ levels in 5 patients. All patients underwent X-ray examination 6 months postoperatively, and satisfactory fusion was observed in $\mathrm{ROI}-\mathrm{C}$ segments.

The JOA score increased from $8.2 \pm 1.5$ preoperatively to $12.3 \pm 0.9$ at 3 months postoperatively $(p<0.05)$ and was 13.6 \pm 1.5 at the final follow-up. The JOA recovery rate between the final follow-up and preoperatively was $64.8 \pm 5.2 \%$. Similarly, the NDI score significantly decreased from $17.9 \pm$ 3.5 preoperatively to $13.7 \pm 5.5$ at 3 months postoperatively $(p<0.05)$ and was $12.2 \pm 6.3$ at the final follow-up. Dysphagia was not found at the final follow-up (Table II).

The cervical curvature, FSA, HOS, and VBP were significantly improved at 3 months postoperatively. At the final follow-up, values were well maintained at $15.5 \pm 6.2,4.8 \pm 5.9,7.1 \pm$ 2.5 , and $10.1 \pm 8.3$, respectively, which were not significantly different than the values obtained at 3 months postoperatively (Table III).

This is a typical case of a 40-year-old male patient admitted to the hospital who was diagnosed with radiculopathy. $\mathrm{He}$ underwent ACCF 5 years ago. The symptoms of left upper extremity pain and numbness worsen over 3 months. The preand postoperative imaging data are shown in Figures $3 \mathrm{~A}-\mathrm{C}$, $4 A-D$.

\section{DISCUSSION}

CSM is a common degenerative disease. It caused severe dysfunction that requires surgery in some patients, especially for those with massive osteophytes or ossification of the posterior ligmentum. ACCF with anterior plate fixation has become the most frequently used surgical option that can directly alleviate decompression, provide satisfactory clinical outcomes in the JOA score and recovery rate. Along with the gradual development of ACCF surgery, several surgeons found that ASD after ACCF surgery may lead to new neurological dysfunction, which may further lead to revision surgery. A previous study showed the cause of ASD after anterior cervical fusion is very complicated, and Wang considered the age of $<50$ years during the operation and developmental canal stenosis were risk factors for ASD after ACDF (27).

Zhao evaluated ASD after an anterior cervical decompression and fusion on X-ray and MRI and concluded that development of cervical canal stenosis and greater disc impingement may be risk factors (39). Once the conservative treatment of ASD
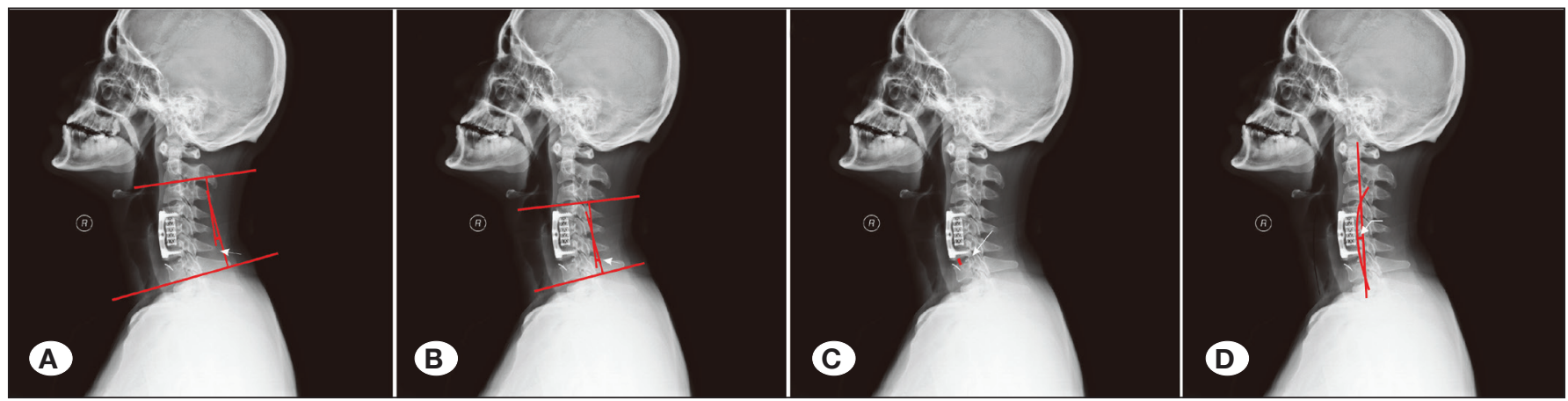

Figure 2: Methods of measuring cervical radiographic parameters. A) Cervical curvature is the angle between the perpendicular line of the inferior endplate of the C2 and C7 vertebrae. B) FSA is the angle between the perpendicular line of the superior end plate of the cranial fusion vertebrae and the inferior endplate of the caudal fusion vertebrae. C) HOS is the height of the operation segment, measured as the distance between the midpoint of the upper endplate and the midpoint of the lower endplate. D) A line was drawn between the upper edge of the posterior odontoid process and the posterior and lower edge of the $\mathrm{C} 7$ vertebra, connecting the posterior margin of the vertebrae to the arc. VBP is the vertical distance from the arc top to the front line. 
Wei H. et al: Adjacent Segment Disease after an Anterior Cervical Corpectomy

Table I: Preoperative and Operative Details of Patients

\begin{tabular}{|c|c|}
\hline Factor & Total $(n=8)$ \\
\hline \multicolumn{2}{|l|}{ Preoperative details } \\
\hline Age $(y r s)^{\star}$ & $51.9 \pm 6.5$ \\
\hline Sex, no. of patients (\% male) & $4(50)$ \\
\hline Body mass index $\left(\mathrm{kg} / \mathrm{m}^{2}\right)^{\star}$ & $32.6 \pm .5$ \\
\hline \multicolumn{2}{|l|}{ Comorbidity, no. of patients (\%) } \\
\hline Hypertension & $2(25)$ \\
\hline Diabetes & $2(25)$ \\
\hline Heart disease & $1(12.5)$ \\
\hline COPD & $1(12.5)$ \\
\hline \multicolumn{2}{|l|}{ Smoking, no. of patients (\%) } \\
\hline None & $3(37.5)$ \\
\hline Quit & $5(63.5)$ \\
\hline Current & $0(0)$ \\
\hline \multicolumn{2}{|l|}{ Diagnosis, (\%) } \\
\hline Radiculopathy & $5(62.5)$ \\
\hline Myelopathy & $2(25)$ \\
\hline Radiculopathy+ Myelopathy & $1(12.5)$ \\
\hline $\begin{array}{l}\text { Operation time before last ACCF surgery } \\
\text { (months) }\end{array}$ & $60.5 \pm 15.5$ \\
\hline Bone density & $-1.5 \pm 1.2$ \\
\hline Mean preop neck VAS score (range $0-10)^{*}$ & $4.6 \pm 2.1$ \\
\hline Mean preop cervical Cobb angle $\left({ }^{\circ}\right)^{*}$ & $1.2 \pm 16.7$ \\
\hline \multirow[t]{3}{*}{ Cervical levels (no. of patients) } & C3-4 (3) \\
\hline & $\mathrm{C} 4-5(2)$ \\
\hline & C5-6 (3) \\
\hline \multicolumn{2}{|l|}{ Operative details } \\
\hline Operative time(minutes) ${ }^{*}$ & $75.6 \pm 18.7$ \\
\hline Blood loss $(\mathrm{mL})$ * & $25.5 \pm 20.5$ \\
\hline Hospital stay after surgery (days) * & $2.5 \pm 1.5$ \\
\hline Follow-up time (months) * & $16.5 \pm 4.5$ \\
\hline
\end{tabular}

COPD: Chronic obstructive pulmonary disease; OPLL: Ossification of posterior longitudinal ligament.

*Values expressed as the mean \pm standard deviation.

is ineffective choosing the proper type of surgery for ASD has aroused the attention of spinal surgeons. Shen used anterior cervical discectomy and fusion (ACDF) for revision surgery (17). If the adjacent segment of the initial operation level needs to be re-operated, the anterior approach is used for revision surgery through the right skin incision, the PEEK cage
Table II: Clinical Evaluation

\begin{tabular}{lc}
\hline Factor & Total $(\mathbf{n}=\mathbf{8})$ \\
\hline JOA scores ${ }^{*}$ & \\
\hline Preoperative & $8.2 \pm 1.5$ \\
\hline Postoperative 3 months & $12.3 \pm 0.9$ \\
\hline Final follow-up & $13.6 \pm 1.5$ \\
\hline JOA RR (\%) & $64.8 \pm 5.2$ \\
\hline NDI scores * & \\
\hline Preoperative & $17.9 \pm 3.5$ \\
\hline Postoperative 3 months & $13.7 \pm 5.5$ \\
\hline Final follow-up & $12.2 \pm 6.3$ \\
\hline Dysphagia rate (\%) & 12.5 \\
\hline Postoperative 2 weeks & 0 \\
\hline Postoperative 3 months & 0 \\
\hline Final follow-up
\end{tabular}

JOA scores and NDI datas post operation compare with preoperation: $p<0.05$

* Values expressed as the mean \pm standard deviation.

or titanium mesh cage is used to fill and apply the anterior plate system, and satisfactory results can be achieved after surgery. Zhang et al. used the finite element analyze the screw sagittal angle (SSA) effect on ASD after ACCF, and found that with the increase of SSA, the stress on the end plate of the adjacent cervical segment decreased (38). Increasing SSA during surgery has an important role in reducing the incidence of ASD. Li et al. evaluate the effectiveness and safety of ACDF, ACCF, cervical total disc replacement (CTDR), and hybrid surgery $(\mathrm{HS})$ in the treatment of CSM. CTDR and ACCF have the lowest incidence of ASD (18).

$\mathrm{ROI}-\mathrm{C}$ is likely to provide immediate stability and prevent plate-related complications with a "zero-profile" structure and is a popular system with the advantages of being simple and compact. In a previous study, ACDF with ROI-C achieved effective clinical treatment for patients with CSM or cervical spondylotic radiculopathy, and the patient had similar or better outcomes compared to ACDF with anterior plating (3). Zhang et al. compared the ACDF with ROI-C and laminoplasty for multilevel CSM, and the clinical efficacy is similar; however, it may lead to decreased range of motion (36). In our study, revision surgery can also get less blood loss, shorter hospital stays, and improved sagittal balance. Basques et al. compared the outcomes between the initial ACDF and the revised ACDF and found that revision surgery can lead to undesirable consequences including thromboembolism, infection of the surgical site, and re-hospitalization (1). Simple and effective surgical treatments are significant for revision ACDF surgery. Based on previous literature and our surgical experience, the ROI-C was used to treat patients with ASD after ACCF, and the clinical efficacy was safe and effective. 
Table III: Radiological Evaluation

\begin{tabular}{lcccc}
\hline & Cervical curvature C2-C7 Cobb angle $\left({ }^{\circ}\right)$ & FSA $\left({ }^{\circ}\right)$ & HOS $\mathbf{m m})$ & VBP $(\mathbf{m m})$ \\
\hline Preoperation & $13.5 \pm 6.8$ & $2.6 \pm 4.6$ & $5.9 \pm 1.5$ & $8.1 \pm 7.4$ \\
\hline 3 months after operation & $15.3 \pm 5.7$ & $4.7 \pm 5.6$ & $7.1 \pm 1.8$ & $9.8 \pm 6.8$ \\
\hline Final follow-up & $15.5 \pm 6.2$ & $4.8 \pm 5.9$ & $7.1 \pm 2.5$ & $10.1 \pm 8.3$ \\
\hline
\end{tabular}

Every datas post operation compare with preoperation: $p<0.05$

Values expressed as the mean \pm standard deviation.
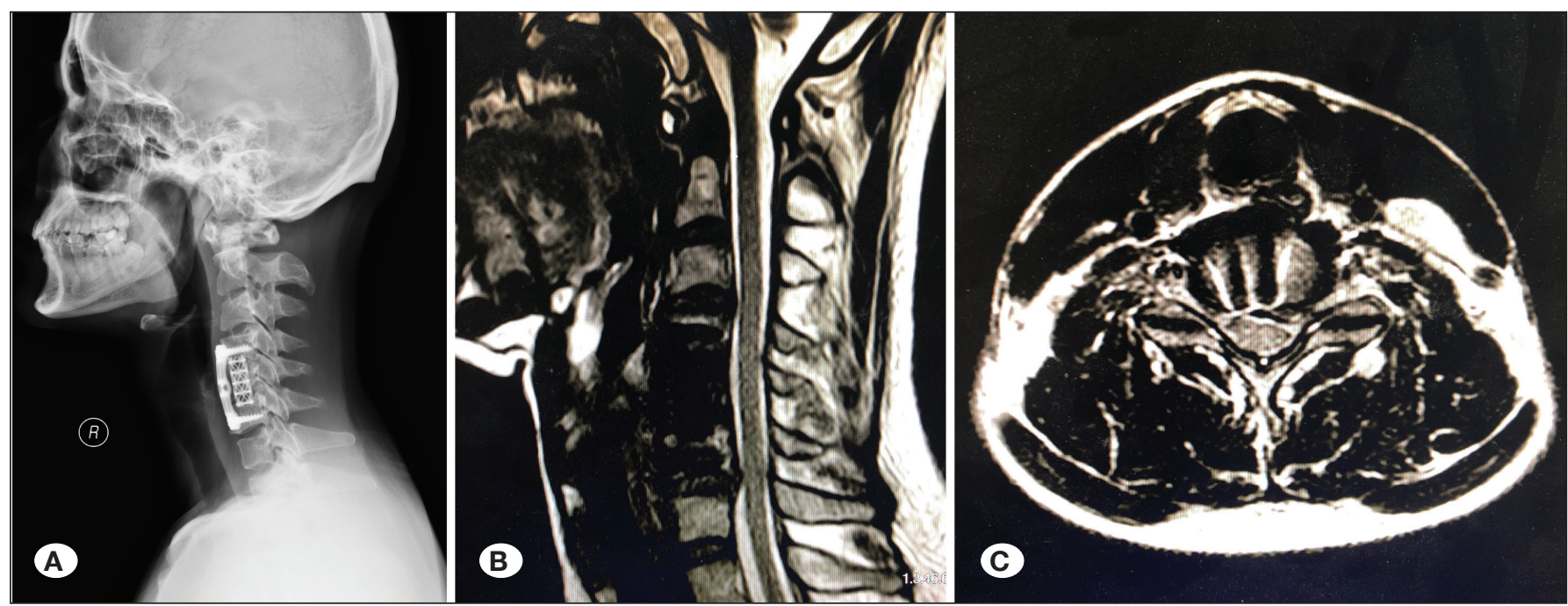

Figure 3: Preoperative imaging examination. A) X-RAY showed decreased physiological bending of the cervical vertebrae. B,C) MRI showed ASD at the inferior ACCF segment, and the dura mater was compressed by the herniate disc. MRI: magnetic resonance imaging.
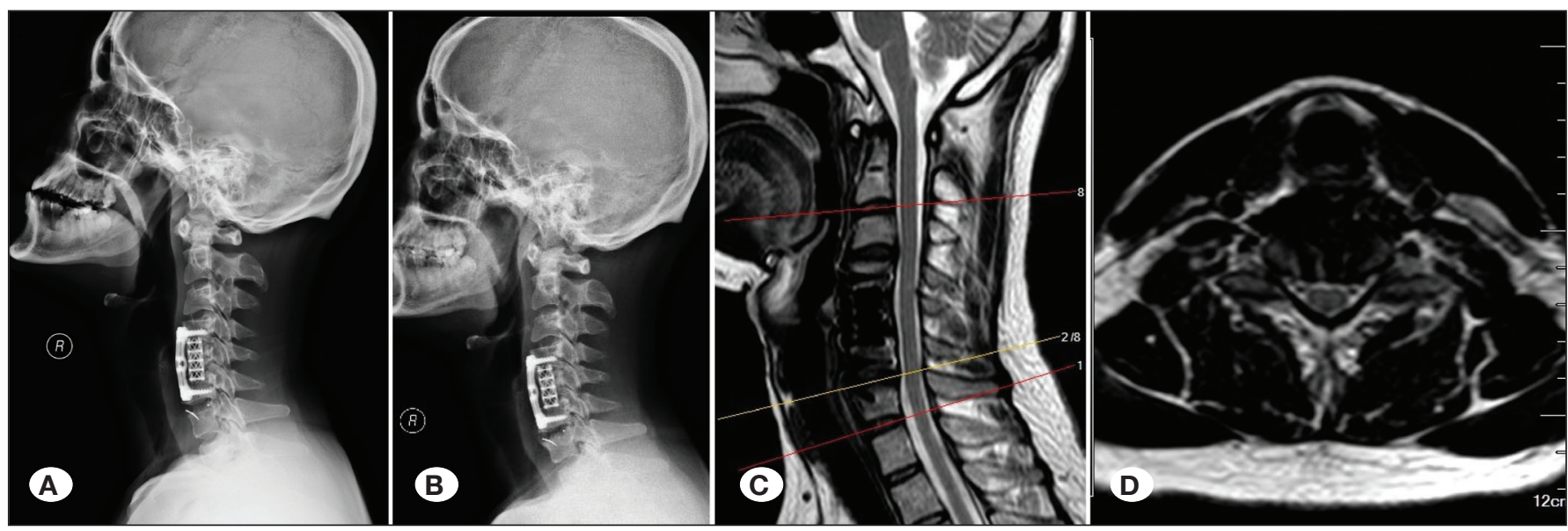

Figure 4: Postoperative imaging examination. A) X-ray imaging showed satisfactory position of ROI-C at 3 days postoperatively. B) $\mathrm{X}$-ray imaging showed the position of ROI-C was well maintained and the curvature of cervical was improved at 1 year postoperatively. C, D) MRI showed satisfactory decompression at the ASD segment. MRI: Magnetic resonance imaging.

Some surgeons were accustomed to use original surgical incision, perform decompression, and fusion in ASD segment after removing the screws and plate, then placed the longer plate across the original ACCF and ASD segments. This procedure can directly alleviate decompression, effectively restore the cervical curvature, and rebuild the stability of ASD segment. However, it may increase the risk of esophageal or tracheal injury, nerve injury, and dysphagia. In addition, this process leads to longer operation time and higher fixation loose rate (21). Other surgeons choose to perform posterior cervical surgery such as single-door laminoplasty or Key-Hole surgery to treat ASD after ACCF. This treatment prevents the 
risk of complication mentioned above, which may be caused by the anterior cervical approach surgery. Conversely, due to indirect decompression, it may not lead to satisfactory clinical outcomes, and complications in the posterior cervical approach surgery may possibly occur (4). We combined the advantage of anterior and posterior cervical surgery and designed a simple, safe, and effective treatment for ASD after ACCF. In our study, disc compression or osteophytes were directly relieved using a microscope, because the selflocking design of ROI-C can simplify the surgical procedure, eliminate the need for screw drilling, and tapping. The titanium plate need not be removed, the ROI-C is placed directly in the adjacent segment, which can shorten the operation time and prevent bleeding as compared to the conventional ACDF operation (19).

Compared with the primary anterior cervical surgery, revision procedures are associated with higher costs, unplanned return to the operating room and complications. The operative time and readmission rates also significantly increase (20). The design of the surgical incision has special significance for the revision surgery, to avoid the original incision, obtain a clearer anatomy, and reduced risk of soft tissue injury. The primary advantage of anterior cervical surgery is the ability to reduce the injury risk to the laryngeal nerve and recurrent laryngeal nerve and esophageal wound infections. We placed the ROI-C using the opposite site approach, and none of the complications mentioned occurred in postoperatively, indicating the opposite site approach has obvious advantage in the revision surgery.

The cervical alignment provides postural strength by force distribution. Restoration of intervertebral height and cervical lordosis can effectively avoid complications such as postoperative cage subsidence, nonunion, and neck and shoulder pain (9). Villavicencio et al. considered that maintaining a consistent segmental sagittal alignment or increasing segmental lordosis was very important during the surgery, which can significantly improve the clinical outcomes (25). However, Xie and Hurlbert suggested that patient selection and surgical decompression were the key factors in achieving desirable clinical efficacy after ACDF, and cervical alignment partially influences clinical outcomes (30). According to our study, adequate decompression of the spinal cord and nerve root was achieved with the help of a microscope during the surgery. The bony endplate was preserved as much as possible before placing the interbody, suitable cages to reduce the tendency toward kyphosis and provide satisfactory stability (5). When the cervical curvature, FSA, HOS, and VBP were $13.5 \pm 6.8$, $2.6 \pm 4.6,5.9 \pm 1.5$, and $8.1 \pm 7.4$, respectively, and were well maintained at $15.5 \pm 6.2,4.8 \pm 5.9,7.1 \pm 2.5$, and $10.1 \pm 8.3$, respectively, at the final follow-up, the radiological evaluation improved significantly $(\mathrm{p}<0.05)$.

Female gender, younger patients, and increased operating time were associated with increased rates of dysphagia in the early postoperative period, and longer-term dysphagia seems to be more associated with pre-existing medical comorbidities
(33). The dysphagia symptom after anterior cervical surgery is commonly characterized by the plate thickness and adhesions attached to the esophagus in the early follow-up period $(28,31)$. In our study, no dysphagia symptom was recorded before the ASD surgery: 1 patient had dysphagia symptom 2 weeks postoperatively, and no dysphagia symptom was recorded at the final follow-up. To consider the advantages of the incision design and the zero-profile design of the $\mathrm{ROI}-\mathrm{C}$, we need a smaller range of surgical exposure, leading to mild esophageal traction, to prevent mechanical irritation of the esophagus and other prevertebral soft tissues.

The limitations of this study are largely related to the small sample size because ROI-C has only been used in the recent years and the number of patients with ASD after ACCF surgery is limited. According to the study design, patients with multisegment ASD and severe osteoporosis were not included in the study; however, these factors may have implications in observing the fusion effects of ROI-C. Lastly, all patients in this study were operated on at a single institution by a single surgeon, and although the patients selected can reduce the research bias, the generalizability may be limited. Further multicenter prospective randomized studies with larger patient samples are needed to confirm the results.

Hsu et al. pretreated female Long-Evans rats with dioxin or vehicle for 6 weeks, and the results showed that cigarette smoking can inhibit bone healing and forms pseudarthrosis (12). Glassman et al. studied the relationship between spinal fusion and quitting smoking, the nonunion rate for nonsmokers, smokers, and patients who quit smoking postoperatively was $14.2 \%, 26.5 \%$, and $17.1 \%$, respectively (8). They concluded that postoperative smoking cessation can help reverse the impact of cigarette smoking. Five patients quit smoking postoperatively in our study, and all the patients achieved fusion at 6 months postoperatively. The results indicate the importance of no smoking and smoking cessation on the perioperative spinal fusion.

\section{CONCLUSION}

In conclusion, the self-locking stand-alone cage is a reliable and effective method used from opposite approach for the treatment of ASD after ACCF. Clinical outcomes were satisfactory in terms of JOA and NDI scores. Clinical results showed high fusion rates and low rates of dysphagia. The curvature of the cervical spine and intervertebral height was effectively improved or maintained during the follow-up period. The operation is relatively simple with less soft tissue damage and reduced complications related to long plate revision.

\section{FUNDING}

This work was supported by the Tianjin Municipal Health Bureau key research projects (16KG158) and Tianjin Municipal Health Bureau Key Projects of Integrated Traditional Chinese and Western Medicine (2019118); Foundation of Tianjin Union Medical Center (2017YJ024, 2018YJ010, 2019JZPY01). 


\section{- REFERENCES}

1. Basques BA, Ondeck NT, Geiger EJ, Samuel AM, Lukasiewicz AM, Webb ML, Bohl DD, Massel DH, Mayo BC, Singh K, Grauer JN: Differences in short-term outcomes between primary and revision anterior cervical discectomy and fusion. Spine (Phila Pa 1976) 42:253-260, 2017

2. Bazaz R, Lee MJ, Yoo JU: Incidence of dysphagia after anterior cervical spine surgery: A prospective study. Spine (Phila Pa 1976) 27:2453-2458, 2002

3. Bucci MN, Oh D, Cowan RS, Davis RJ, Jackson RJ, Tyndall DS, Nehls D: The ROI-C zero-profile anchored spacer for anterior cervical discectomy and fusion: Biomechanical profile and clinical outcomes. Medical Devices (Auckland, NZ) 10:6169, 2017

4. Bydon M, Xu R, De la Garza-Ramos R, Macki M, Sciubba DM, Wolinsky JP, Witham TF, Gokaslan ZL, Bydon A: Adjacent segment disease after anterior cervical discectomy and fusion: Incidence and clinical outcomes of patients requiring anterior versus posterior repeat cervical fusion. Surg Neurol Int 5:S74-78, 2014

5. Chen Y, Lu G, Wang B, Li L, Kuang L: A comparison of anterior cervical discectomy and fusion (ACDF) using self-locking stand-alone polyetheretherketone (PEEK) cage with ACDF using cage and plate in the treatment of three-level cervical degenerative spondylopathy: A retrospective study with 2-year follow-up. Eur Spine J 25:2255-2262, 2016

6. Dickerman RD, Reynolds AS, Bennett M: Cervical spondylotic myelopathy: A complex problem where approach is patient dependent. Eur Spine J 19:150-151, 2010

7. Gillis CC, Kaszuba MC, Traynelis VC: Cervical radiographic parameters in 1- and 2-level anterior cervical discectomy and fusion. J Neurosurg Spine 25:421-429, 2016

8. Glassman SD, Anagnost SC, Parker A, Burke D, Johnson JR, Dimar JR: The effect of cigarette smoking and smoking cessation on spinal fusion. Spine (Phila Pa 1976) 25:26082615, 2000

9. Godlewski B, Stachura MK, Czepko RA, Banach M, Czepko $R$ : Analysis of changes in cervical spinal curvature and intervertebral disk space height following ACDF surgery in a group of 100 patients followed up for 12 months. J Clin Neurosci 52:92-99, 2018

10. Gok B, Sciubba DM, McLoughlin GS, McGirt M, Ayhan S, Wolinsky JP, Bydon A, Gokaslan ZL, Witham TF: Revision surgery for cervical spondylotic myelopathy: surgical results and outcome. Neurosurgery 63:292-298; discussion 298, 2008

11. Hirabayashi K, Miyakawa J, Satomi K, Maruyama T, Wakano $\mathrm{K}$ : Operative results and postoperative progression of ossification among patients with ossification of cervical posterior longitudinal ligament. Spine (Phila Pa 1976) 6:354364, 1981

12. Hsu EL, Sonn K, Kannan A, Bellary S, Yun C, Hashmi S, Nelson J, Mendoza M, Nickoli M, Ghodasra J, Park C, Mitchell S, Ashtekar A, Ghosh A, Jain A, Stock SR, Hsu WK: Dioxin exposure impairs BMP-2-mediated spinal fusion in a rat arthrodesis model. Journal of Bone and Joint Surgery 97:1003-1010, 2015
13. Kan L, Kang J, Gao R, Chen X, Jia L: Clinical and radiological results of two hybrid reconstructive techniques in noncontiguous 3-level cervical spondylosis. J Neurosurg Spine 21:944-950, 2014

14. Kepler CK, Hilibrand AS: Management of adjacent segment disease after cervical spinal fusion. Orthop Clin North Am 43:53-62, 2012

15. Lau D, Chou D, Mummaneni PV: Two-level corpectomy versus three-level discectomy for cervical spondylotic myelopathy: A comparison of perioperative, radiographic, and clinical outcomes. J Neurosurg Spine 23:280-289, 2015

16. Lebl DR, Bono CM: Update on the diagnosis and management of cervical spondylotic myelopathy. J Am Acad Orthop Surg 23:648-660, 2015

17. Li J, Tong T, Niu R, Shen Y: A study on the clinical outcomes of patients with revision surgery for adjacent segment disease after 10-year's anterior cervical spine surgery. J Orthop Surg Res 11:5, 2016

18. Li Z, Chen L, Li B, Wei J: Efficacy and safety of surgical interventions for treating multilevel cervical spondylotic myelopathy via anterior approach: A network meta-analysis. Pain Physician 22:E275-E286, 2019

19. Luo J, Huang S, Gong M, Li L, Yu T, Zou X: Two-level anterior cervical discectomy and fusion using self-locking stand-alone polyetheretherketone cages with two anchoring clips placed in the upper and lower vertebrae, respectively. Eur J Orthop Surg Traumatol 25 Suppl 1:S147-153, 2015

20. Nandyala SV, Marquez-Lara A, Fineberg SJ, Singh K: Comparison of revision surgeries for one- to two-level cervical TDR and ACDF from 2002 to 2011. Spine J 14:2841-2846, 2014

21. Niedzielak TR, Palmer J, Malloy JP: Clinical comparison of surgical constructs for anterior cervical corpectomy and fusion in patients with cervical spondylotic myelopathy or ossified posterior longitudinal ligament: A systematic review and meta-analysis. Clin Spine Surg 31:247-260, 2018

22. Puvanesarajah V, Jain A, Cancienne JM, Shimer AL, Singla A, Shen F, Hassanzadeh $\mathrm{H}$ : Complication and reoperation rates following surgical management of cervical spondylotic myelopathy in medicare beneficiaries. Spine (Phila Pa 1976) 42:1-7, 2017

23. Thome C, Krauss JK, Zevgaridis D: A prospective clinical comparison of rectangular titanium cages and iliac crest autografts in anterior cervical discectomy and fusion. Neurosurg Rev 27:34-41, 2004

24. Vernon H, Mior S: The neck disability index: A study of reliability and validity. J Manipulative Physiol Ther 14:409-415, 1991

25. Villavicencio AT, Babuska JM, Ashton A, Busch E, Roeca C, Nelson EL, Mason A, Burneikiene S: Prospective, randomized, double-blind clinical study evaluating the correlation of clinical outcomes and cervical sagittal alignment. Neurosurgery 68:1309-1316; discussion 1316, 2011

26. Virk SS, Phillips FM, Khan SN: Bundled payment reimbursement for anterior and posterior approaches for cervical spondylotic myelopathy: An analysis of private payer and Medicare databases. J Neurosurg Spine 28:244-251, 2018 
Wei H. et al: Adjacent Segment Disease after an Anterior Cervical Corpectomy

27. Wang F, Hou HT, Wang P, Zhang JT, Shen Y: Symptomatic adjacent segment disease after single-lever anterior cervical discectomy and fusion: Incidence and risk factors. Medicine (Baltimore) 96:e8663, 2017

28. Wu B, Song F, Zhu S: Reasons of dysphagia after operation of anterior cervical decompression and fusion. Clin Spine Surg 30:E554-E559, 2017

29. Xiao SW, Jiang $\mathrm{H}$, Yang LJ, Xiao ZM: Anterior cervical discectomy versus corpectomy for multilevel cervical spondylotic myelopathy: A meta-analysis. Eur Spine J 24:3139, 2015

30. Xie JC, Hurlbert RJ: Discectomy versus discectomy with fusion versus discectomy with fusion and instrumentation: A prospective randomized study. Neurosurgery 61:107-116; discussion 116-117, 2007

31. Yagi K, Nakagawa H, Okazaki T, Irie S, Inagaki T, Saito O, Nagahiro S, Saito K: Noninfectious prevertebral soft-tissue inflammation and hematoma eliciting swelling after anterior cervical discectomy and fusion. J Neurosurg Spine 26:459465, 2017

32. Yang HS, Chen DY, Lu XH, Yang LL, Yan WJ, Yuan W, Chen $Y$ : Choice of surgical approach for ossification of the posterior longitudinal ligament in combination with cervical disc hernia. Eur Spine J 19:494-501, 2010

33. Yew AY, Nguyen MT, Hsu WK, Patel AA: Quantitative risk factor analysis of postoperative dysphagia after anterior cervical discectomy and fusion (ACDF) using the eating assessment tool-10 (EAT-10). Spine (Phila Pa 1976) 44:E82-E88, 2019
34. Yonenobu K, Abumi K, Nagata K, Taketomi E, Ueyama K: Interobserver and intraobserver reliability of the japanese orthopaedic association scoring system for evaluation of cervical compression myelopathy. Spine (Phila $\mathrm{Pa}$ 1976) 26:1890-1894; discussion 1895, 2001

35. Yoshii T, Hirai T, Sakai K, Sotome S, Enomoto M, Yamada T, Inose H, Kato T, Kawabata S, Okawa A: Anterior cervical corpectomy and fusion using a synthetic hydroxyapatite graft for ossification of the posterior longitudinal ligament. Orthopedics 40:e334-e339, 2017

36. Zhang J, Liu H, Bou EH, Jiang W, Zhou F, He F, Yang H, Liu T: Comparative study between anterior cervical discectomy and fusion with ROI-C cage and laminoplasty for multilevel cervical spondylotic myelopathy without spinal stenosis. World Neurosurg 121:e917-e924, 2019

37. Zhang Y, Liu H, Yang H, Pi B: Anterior cervical corpectomy and fusion versus discectomy and fusion for the treatment of two-level cervical spondylotic myelopathy: Analysis of sagittal balance and axial symptoms. Int Orthop 42:1877-1882, 2018

38. Zhang Y, Tang Y, Shen H: Relationship between screw sagittal angle and stress on endplate of adjacent segments after anterior cervical corpectomy and fusion with internal fixation: A Chinese finite element study. BMC Surg 17:119, 2017

39. Zhao Y, Sun Y, Zhou F, Wang S, Zhang F, Pan S: Adjacent segment disease after anterior cervical decompression and fusion: Analysis of risk factors on X-ray and magnetic resonance imaging. Chinese Medical Journal 127:3867-3870, 2014 